\title{
Familial insulin resistance with pineal hyperplasia: metabolic studies and effect of hypophysectomy
}

\author{
RICHARD J WEST AND JAMES V LEONARD \\ Department of Child Health, Institute of Child Health, London
}

SUMMARY Mendenhall's syndrome comprises insulin-resistant diabetes, pineal hyperplasia, and various somatic anomalies. A boy with this condition now aged 12 years is reported; a similarly affected sibling died aged 7.8 years. Hypophysectomy has been of short-term benefit, but the problems of insulin resistance persist. On the basis of monocyte-binding studies it seems likely that in this condition there is an inherited deficiency of insulin receptors.

Mendenhall ${ }^{1}$ described 3 siblings with unusual facies, dental precocity and dysplasia, thickened nails, hirsutism, acanthosis nigricans, abdominal protruberance, and phallic enlargement. All 3 died in midchildhood from insulin-resistant diabetes mellitus and at necropsy there was pineal hyperplasia. ${ }^{2}$ We previously described a further 2 siblings with this syndrome and showed that the insulin resistance could not be explained by excess production of corticosteroids, glucagon, or growth hormone, nor was it explained by circulating insulin antibodies. The elder sibling died at age $7 \cdot 8$ years; necropsy confirmed pineal hyperplasia. ${ }^{3}$ We now report further studies, and the progress of the second child, who has had a hypophysectomy for life-threatening diabetic ketoacidosis.

\section{Case report}

This boy was the second child of unrelated parents. He was born at term weighing $2.3 \mathrm{~kg}$, and unusual facies and abdominal distension were noted at birth. An abnormal dentition started at 4 months. ${ }^{4}$ Developmental progress was normal.

From his appearance it was apparent that he had the same syndrome as his elder sister, so he was first studied, before he had any symptoms, at age $3 \cdot 1$ years. At that time he was well nourished, and both weight and height were between the 3rd and 10th centiles. There was acanthosis nigricans of neck, axillae, and cubital fossae. The nails were thickened, there was moderate hypertrichosis, the teeth were dysplastic, and the tongue fissured. There was penile enlargement, but no pubic hair or testicular enlargement.

Oral glucose tolerance tests were performed, first at age 3.1 years, and at intervals thereafter (Fig. 1).
Serum insulin levels were grossly raised on each occasion, confirming that insulin resistance had been present from an early age.

He remained well until 6.8 years, when he gradually developed increasing thirst and polyuria. Fasting blood glucose varied between 11.0 and 15.0 $\mathrm{mmol} / \mathrm{l}(200-275 \mathrm{mg} / 100 \mathrm{ml})$, and urine volume was 3-4 litres daily. He was ketonuric and hypokalaemic, and oral potassium supplements were started. This development of hyperglycaemia was accompanied by a fall in concentration of serum insulin, suggesting islet cell failure. It was known from experience with his sister that only extremely large doses of insulin would be likely to have an effect on blood sugar, and as these would have been impracticable for
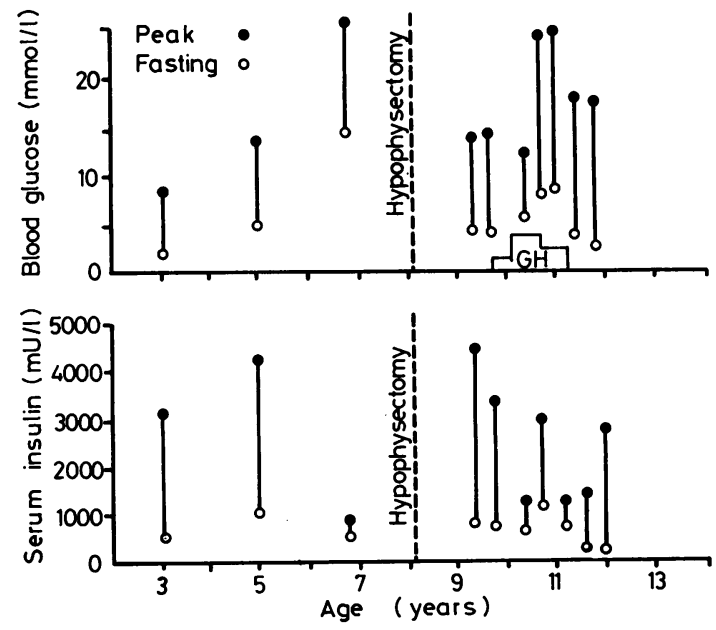

Fig. 1 Fasting and peak levels during glucose tolerance tests. 
maintenance therapy, no insulin was given at that time.

For the next year he remained in reasonable health, but with persistent glycosuria, ketonuria, and increasing polyuria. At age 8 years his condition suddenly deteriorated and he was admitted to hospital semi-conscious with dehydration and acidosis. Blood glucose concentration was 34.5 $\mathrm{mmol} / 1(620 \mathrm{mg} / 100 \mathrm{ml})$. Dehydration and acidosis were corrected with intravenous fluids, but exogenous insulin was not given initially because of the known insulin resistance. For the next week he was maintained on intravenous fluids but he remained hyperglycaemic, with a urine output of up to 15 litres a day. Hypophysectomy was felt to offer the best chance of significant improvement in the diabetic state. To improve his metabolic state before operation, neutral insulin injection (Actrapid $\mathrm{MC}^{*}$ ) $200 \mathrm{U} / \mathrm{ml}$ was given by continuous intravenous infusion with a syringe pump. A total of 26240 units insulin was infused over a $12 \frac{1}{2}$-hour period during which time the blood glucose gradually decreased from an initial concentration of $24 \mathrm{mmol} / \mathrm{l}(430 \mathrm{mg} /$ $100 \mathrm{ml})$ to $9.0 \mathrm{mmol} / \mathrm{l}(164 \mathrm{mg} / 100 \mathrm{ml})$. Thereafter doses of 11000-20000 units were given daily until hypophysectomy 9 days later, dosage being adjusted to maintain normoglycaemia (Fig. 2).

Hypophysectomy was performed via a frontal bone flap with suction removal of the pituitary. Replacement therapy with DDAVP, cortisone acetate, and thyroxine was started, and has been continued.

Immediately after the hypophysectomy insulin requirements fell, and good control of blood sugar * Novo.

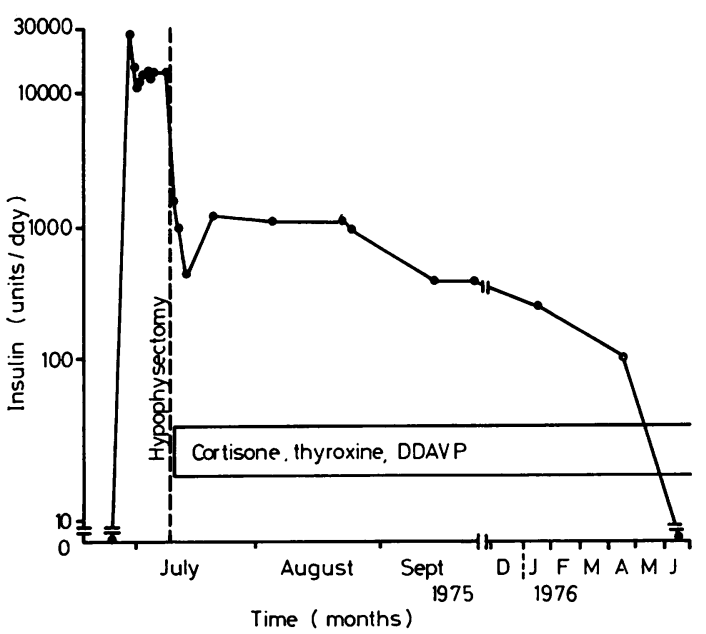

Fig. 2 Daily insulin requirements. was obtained with pulsed doses of insulin, giving about 200 units every 3-4 hours. Within a few days of operation insulin requirements had stabilised at about 1000 units daily, and this was then given by twice-daily subcutaneous injections. Daily insulin requirements gradually decreased and exogenous insulin was stopped 11 months after the operation. Nevertheless, he still has an abnormal glucose tolerance test and insulin resistance (Fig. 1).

Pituitary function tests during the $1 \frac{1}{2}$ years since operation have indicated no residual function, but subsequently very low amounts of prolactin and growth hormone have been detectable in the plasma. During the 4 years since operation he has remained well and active, but growth has been poor. Height velocity averaged $1.7 \mathrm{~cm}$ a year between operation and starting replacement therapy with growth hormone (GH). GH was started in a dose of $2 \mathrm{mg}$ twice weekly at age $9 \cdot 8$ years and was increased to $5 \mathrm{mg}$ thrice weekly at age $10 \cdot 2$ years. On this dose there was decreasing glucose tolerance with frequent glycosuria (Fig. 1). The dose was reduced to $5 \mathrm{mg}$ twice weekly at 10.8 years, and stopped at 11.4 years. Height velocity while on GH was $2 \cdot 1 \mathrm{~cm}$ a year. The plasma somatomedin response to $\mathrm{GH}$ was normal. Glucose tolerance is better now that GH injections have been stopped.

Measurement of insulin binding to monocytes, using the method of Khan et al., ${ }^{5} 3 \frac{1}{2}$ years after hypophysectomy and at a time when he had been off GH therapy for 3 months, showed that specific insulin binding was only $26 \%$ of normal.

\section{Discussion}

Hypophysectomy is rarely undertaken in childhood as it has profound consequences on growth and sexual development, but there seems little doubt that this boy would have died of diabetic ketoacidosis without the operation. The degree of insulin resistance was such that routine treatment with insulin was not practicable and without insulin treatment his condition was deteriorating.

The demonstration of markedly reduced insulin binding of monocytes in this boy suggests deficiency of insulin receptors as a major factor in causing the insulin resistance, as in the 3 patients studied by Khan et al. ${ }^{5}$ who had a syndrome comprising acanthosis nigricans, insulin resistance, hirsutism, and in one patient, clitoromegaly. Other factors may be contributing to the insulin resistance, but glucocorticoids, glucagon, and GH had been shown not to be present in excess, nor were there insulin antibodies or pro insulin. ${ }^{3}$ Lessening of the degree of insulin resistance was apparent immediately after 
hypophysectomy in this boy, but the relatively high daily requirements of exogenous insulin in the 10 months after surgery, and the extremely high serum insulin values measured since operation show that pronounced insulin resistance persists. The lessening of insulin resistance noted after hypophysectomy may well have been due to the removal of pituitary GH.

Despite the improvement, the long-term management of this boy remains unsatisfactory. His growth rate is poor, even with treatment with $\mathrm{GH}$, and such treatment also causes hyperglycaemia. Insulin resistance persists, and if this is due to inherited receptor deficiency it may not be susceptible to change. Further studies on this boy are in progress.

We thank Mr Norman Grant for performing the hypophysectomy, Professor O H Wolff and Professor J K Lloyd for their help, Mrs Lisa Ang for performing the binding studies, and Dr M A Preece for the somatomedin assays.

\section{References}

1 Mendenhall E N. Tumor of the pineal body with high insulin resistance. J Indiana State Med Assoc 1950; 43: 32-6.

2 Rabson S M, Mendenhall E N. Familial hypertrophy of pineal body, hyperplasia of adrenal cortex, and diabetes mellitus. Am J Clin Pathol 1956; 26: 283-90.

3 West R J, Lloyd J K, Turner W M L. Familial insulin resistant diabetes, multiple somatic anomalies, and pineal hyperplasia. Arch Dis Child 1975; 50: 703-8.

4 Holmes J, Tanner M S. Premature eruption and macrodontia associated with insulin resistant diabetes and pineal hyperplasia. Br Dent $J$ 1976; 141 : 280-4.

5 Khan C R, Flier J S, Bar R S, Archer J A, Gordon P, Martin M M, Roth J. The syndromes of insulin resistance and acanthosis nigricans. $N$ Engl $J$ Med 1976; 294: 739-45.

Correspondence to Dr R J West, Department of Child Health, St George's Hospital, Blackshaw Road, London SW17 0QT.

Received 21 August 1979

\section{British Paediatric Association Junior Staff Group Meeting, Friday, 3 October 1980}

This meeting will be held at the Royal Hospital for Sick Children, Bristol, and is open to all interested junior paediatric staff. The guest lecture will be entitled 'Childbirth: a changing scene' and will be given by Dr P M Dunn, Reader in Perinatal Medi- cine. In the evening there will be a dinner for participants and their wives/husbands (approximate cost $£ 6$ per head). The meeting is recognised officially for study leave.

The registration fee is $£ 8$. Applications and papers should be submitted to the organiser, Dr John Osborne, Royal Hospital for Sick Children, St Michael's Hill, Bristol BS2 8BJ. 